\title{
Improving electrocardiogram interpretation skills for medical students
}

This article was published in the following Dove Press journal:

Advances in Medical Education and Practice

16 January 2017

Number of times this article has been viewed

Kunj Patel'

Omar El Tokhy'

Shlok Patel ${ }^{2}$

Hanna Maroof ${ }^{3}$

'Department of Investigative Medicine, Faculty of Medicine, Imperial College London, ${ }^{2}$ Department of Medical Research, Faculty of Medicine, Barts and The London School of Medicine and Dentistry, ${ }^{3}$ GKT School of Medical Education, Faculty of Life Sciences and Medicine, King's College of London, London, UK

Correspondence: Shlok Patel Faculty of Medicine, Barts and The London School of Medicine and Dentistry, 64 Turner Street, London EI 2AD, UK

Email shlok.patel@smdI5.qmul.ac.uk

\section{Dear editor}

We read with great interest the article by Zeng at $\mathrm{al}^{1}$ who propose a new electrocardiogram (ECG) teaching method called the "graphics-sequence memory method". An ECG is one of the most important diagnostic tests and is currently used as a gold standard for the diagnosis of a number of cardiac diseases. We appreciate that it can be a challenging concept to teach, often bringing frustration to the educators trained in ECG interpretation. Zeng et al ${ }^{1}$ highlight a deficiency in learning through the traditional Chinese disease-based teaching method, resulting in a relative inability to interpret ECGs where the diagnosis is not quite so straightforward. Accumulation of evidence ${ }^{2}$ has suggested that a significant proportion of undergraduate medical students do not feel competent in their interpretation of an ECG. Therefore, the authors are right to suggest a novel approach with the dual benefit of aiding teaching and improving learning and confidence when interpreting an ECG.

As current medical students who have already been taught ECG interpretation, we can vouch for the complexities of an ECG trace and the challenges posed in trying to master its analysis. At our institutions, a more integrated approach is currently adopted. In addition to traditional learning using a mixture of textbooks and lectures, an approach similar to the aforementioned "graphics-sequence memory method" is being trialled to aid ECG interpretation. This novel method of teaching is one that we feel would have been extremely beneficial to our learning. Such an approach allows students to carry out a step-by-step analysis, ensuring that crucial ECG waveforms and, therefore, diagnoses are not missed.

Despite our appreciation for the article, we believe that there is still further room for improvement to the technique. Self-directed learning is an important part of the study of medicine, especially with limited teaching time and resources available. We believe that an introduction of a web-based ECG teaching module could potentially prove beneficial. Although previous studies that have developed a readily available web-based teaching module have demonstrated its effectiveness, ${ }^{3,4}$ a sufficiently powered randomized controlled trial similar to the one implemented by Zeng et al ${ }^{1}$ investigating outcomes following web-based ECG teaching is required to confirm this hypothesis.

At Imperial College London, a combination of e-modules alongside traditional learning methods is applied in an effort to familiarize students with common 
cardiac pathologies. Furthermore, the continuous availability of these resources throughout the year has been shown to be especially beneficial. A recent case-control study by Chudgar et $\mathrm{al}^{5}$ assessing the efficacy of an ECG teaching module demonstrated a significant increase in confidence and improved ability to interpret an ECG by students, in comparison to those who did not have access to the module. This suggests that an integrated step-by-step approach to ECG teaching is more effective than any single methodology.

In conclusion, we recommend implementation of the novel teaching technique described by Zeng et al. ${ }^{1}$ It is hoped that this will result in a more thorough ECG approach and, therefore, improved interpretation by students. The addition of web-based teaching modules could potentially be used as a learning aid.

\section{Disclosure}

The authors report no conflicts of interest in this communication.

\section{References}

1. Zeng R, Yue RZ, Tan CY, et al. New ideas for teaching electrocardiogram interpretation and improving classroom teaching content. Adv Med Educ Pract. 2015;6:99-104.

2. Little B, Mainie I, Ho KJ, Scott L. Electrocardiogram and rhythm strip interpretation by final year medical students. Ulster Med J. 2001;70(2):108-110.

3. Nilsson M, Bolinder G, Held C, Johansson BL, Fors U, Ostergren J. Evaluation of a web-based ECG-interpretation programme for undergraduate medical students. BMC Med Educ. 2008;8:25.

4. Nathanson LA, Safran C, McClennen S, Goldberger AL. ECG WaveMaven: a self-assessment program for students and clinicians. Proc AMIA Symp. 2001:488-492.

5. Chudgar SM, Engle DL, Grochowski CO, Gagliardi JP. Teaching crucial skills: an electrocardiogram teaching module for medical students. J Electrocardiol. 2016;49(4):490-495. 


\section{Authors' reply \\ Zeng Rui' \\ Yue Rong-zheng ${ }^{2}$ \\ Tan Chun-yu ${ }^{3}$ \\ Wang Qin ${ }^{4}$ \\ Kuang $\mathrm{Pu}^{5}$ \\ Tian Pan-wen ${ }^{6}$ \\ Zuo Chuan ${ }^{3}$}

'Department of Cardiovascular diseases, ${ }^{2}$ Department of Nephrology, ${ }^{3}$ Department of Rheumatology and Immunology, ${ }^{4}$ Department of Endocrinology, ${ }^{5}$ Department of Hemotology, ${ }^{6}$ Department of Respiratory diseases, West China Hospital, School of Clinic Medicine, Sichuan University, Chengdu, People's Republic of China

Correspondence: Zuo Chuan

Department of Rheumatology and Immunology, West China Hospital, School of Clinic Medicine, Sichuan University, Chengdu 61004I,

People's Republic of China

Tel +862885422343

Fax +862885423249

Email zengrui_0524@I26.com

\section{Dear editor}

I read the letter by Patel et al entitled "Improving Electrocardiogram Interpretation Skills for Medical Students." First, I will give my thanks for all authors in this article for their kind words and interest in my work. ${ }^{1}$ Second, I want to further explain what is the meaning of graphics-sequenced interpretation of electrocardiogram (ECG) and what is the effect as a tool for flipped classroom teaching model.

From my perspective, graphics-sequenced interpretation of ECG can be characterized by two keywords. The first one is graphics. It means that when teaching ECG, schematic diagrams of normal and abnormal ECGs are shown to students. This intuitive approach could make morphology of normal and abnormal ECG clearly understood. The second keyword is sequence. It means that when students learn to analyze ECG, they should follow the specific sequence of ECG waveform generation, namely, the analysis of heart rate and rhythm, the $\mathrm{P}$ wave, PR interval period, QRS wave, ST segment and T wave, QT interphase, and U wave. After getting used to this simple and practical method in ECG interpretation, students will discover how easy it is to read an ECG strip and at the same time avoid omissions in the diagnosis of abnormal conditions.
Two years after we used this method for our ECG teaching, we performed decomposition and refined the knowledge, compiled the script, produced micro-video lessons verified by a team of experts, and uploaded the videos online. Each video was accompanied by questions and exercises to guide ECG self-learning and test learning outcomes. A randomized controlled trial (RCT) study was also performed to compare the study effect between the traditional teaching method and flipped classroom teaching method. The two groups of students received the same textbook, ${ }^{2}$ the same syllabus, and the same practical guidance. They also had the same instructors, teaching schedule, and examination format. The article called "Friend or foe? Flipped Classroom for Undergraduate Electrocardiogram Learning by a Randomized Controlled Study" is now revised by BMC medical education.

This study recognizes the challenge of teaching ECG and focuses on enabling medical students to master ECG interpretation skills through the use of a flipped teaching model. We believe that our study makes a significant contribution to the literature because, through employment of a RCT on ECG learning, it demonstrates that the utilization of the flipped classroom model in teaching ECG has advantages over the traditional teaching method regarding the level of knowledge acquired.

Further, we believe that this article will be of interest to the readership because the research reveals that flipped classroom teaching can improve medical students' interest in learning. Furthermore, it is the first study to use flipped classroom teaching for the learning of ECG in medical diagnosis within People's Republic of China. Therefore, we believe that it is an effective teaching model that is relevant and of interest to all other readers.

\section{Disclosure}

The authors report no conflicts of interest in this communication.

\section{References}

1. Zeng R, Yue RZ, Tan CY, et al. New ideas for teaching electrocardiogram interpretation and improving classroom teaching content. Adv Med Educ Pract. 2015;6:99-104.

2. Zeng R. Graphics-Sequenced Interpretation of ECG. Singapore: Springer; 2015 . 
Dove Medical Press encourages responsible, free and frank academic debate. The content of the Advances in Medical Education and Practice 'letters to the editor' section does not necessarily represent the views of Dove Medical Press, its officers, agents, employees, related entities or the Advances in Medical Education and Practice editors. While all reasonable steps have been taken to confirm the content of each letter, Dove Medical Press accepts no liability in respect of the content of any letter, nor is it responsible for the content and accuracy of any letter to the editor.

Advances in Medical Education and Practice

Dovepress

\section{Publish your work in this journal}

Advances in Medical Education and Practice is an international, peerreviewed, open access journal that aims to present and publish research on Medical Education covering medical, dental, nursing and allied health care professional education. The journal covers undergraduate education, postgraduate training and continuing medical education including emerging trends and innovative models linking education, research, and health care services. The manuscript management system is completely online and includes a very quick and fair peer-review system. Visit http://www.dovepress.com/testimonials.php to read real quotes from published authors.

Submit your manuscript here: http://www.dovepress.com/advances-in-medical-education-and-practice-journal 